\title{
MECANISMOS PERFORMATIVOS DEL GÉNERO COMO PODER: LA ORTOPEDIA SOCIAL Y LA NORMALIZACIÓN DE LA MASCULINIDAD. ${ }^{1}$
}

\author{
PERFORMATIVE MECHANISMS OF THE GENDER AS POWER: THE SOCIAL ORTHOPEDICS \\ AND STANDARDIZATION OF MASCULINITY.
}

Por: Germán Betancourth Morales", Elena Calvo Cuentas**

*GERMÁN BETANCOURTH MORALES

Historiador (Universidad de Cartagena). Magister en Estudios de Género (Univerdidad Nacional de Colombia). Docente de la Universidad de Cartagena y director de Grupo de Investigación Panóptico de los Programas de Educación Distancia de la Universidad

Cartagena (Colombia). $E$-mail: Cartagena(Colombia).E-mail: gbetancourthmorales@ yahoo.es.

**ELENA CALVO

CUENTAS

Psicóloga. Docente de Cátedra de la Universidad de Cartagena. Adscrita al Grupo Panóptico: Estudios Sociales de la Ciencia y la Tecnología de los Programas de Educación a Distancia. Universidad de Cartagena (Colombia).

Artículo tipo 2 de investigación científica y tecnológica según clasificación Colciencias.

${ }^{1}$ El trabajo es producto de una investigación que se realizó con el apoyo de la Universidad Nacional de Colombia, sobre los mecanismos disciplinarios que se emplean para el proceso de normalización de la masculinidad, algunos de cuyos resultados han sido publicados en el libro El verbo hacer dos en el libro El verbo hacer en las investigaciones de género (2010) editado por la Universidad Nacional y la Universidad de Cartagena. Los resultados son revisados con base a una parte de entrevistas $y$ discusiones teóricas, realizadas por el grupo de investigación Panóptico: Estudios sociales de la ciencia y la tecnología.
Artículo Recibido: Mayo 10 de 2010. Artículo Aprobado: Julio 9 de 2010. Páginas: 182-197

"Del objeto, lo abyecto no tiene más que una cualidad, la de oponerse al yo" Julia Kristeva.

"...Lo siento Victoria, ella me hace sentir un verdadero hombre" Diálogo escuchado en la novela mexicana "Victoria".

\section{RESUMEN}

El género se ha concebido como la construcción social de los cuerpos sexuados. En este artículo se desvinculará la relación del género como construcción, abordando la noción de materialización como elemento que permite revisar el concepto mismo como agente productor de los cuerpos que intenta controlar y describir. Explicar el género no como el resultado de unas relaciones de poder, sino como un poder en si mismo que fabrica los sujetos con género, establece las interpretaciones de los cuerpos, da coherencia a las normativas heterosexuales de masculinidad y feminidad, y a su vez permite la configuración de mecanismos de normalización a través de procesos de castigo y vigilancia.

El presente trabajo intenta proporcionar una lectura del concepto de género en su interpretación como un poder social desde el proceso de materialización de la masculinidad, a partir de referencias performativas que instituyen un efecto-ilusión de estabilidad natural y coherente en el cuerpo masculino. Este es un trabajo teórico que se sustenta en las historias de hombres que han sido hechos y deshechos por los mecanismos restrictivos de género y que permite hacer una re-lectura del concepto de género en su práctica de sujeción y construcción de subjetividades.

Palabras clave: Género, sujeción, poder, cuerpo, performatividad.

\section{ABSTRACT}

Gender is conceived as the social construction of sexed bodies. In this article we will detach the relationship between gender as the construction, addressing the notion of embodiment elements that allow you to review the concept as bodies agent, that are trying to control and describe. To explain the gender not as a result of power relations, but as a power within itself that build the gender subjects, establishing interpretations of the bodies, giving coherence to heterosexual norms of masculinity and femininity, and in turn allows configuration of normalization mechanisms through punishment and monitoring processes. 


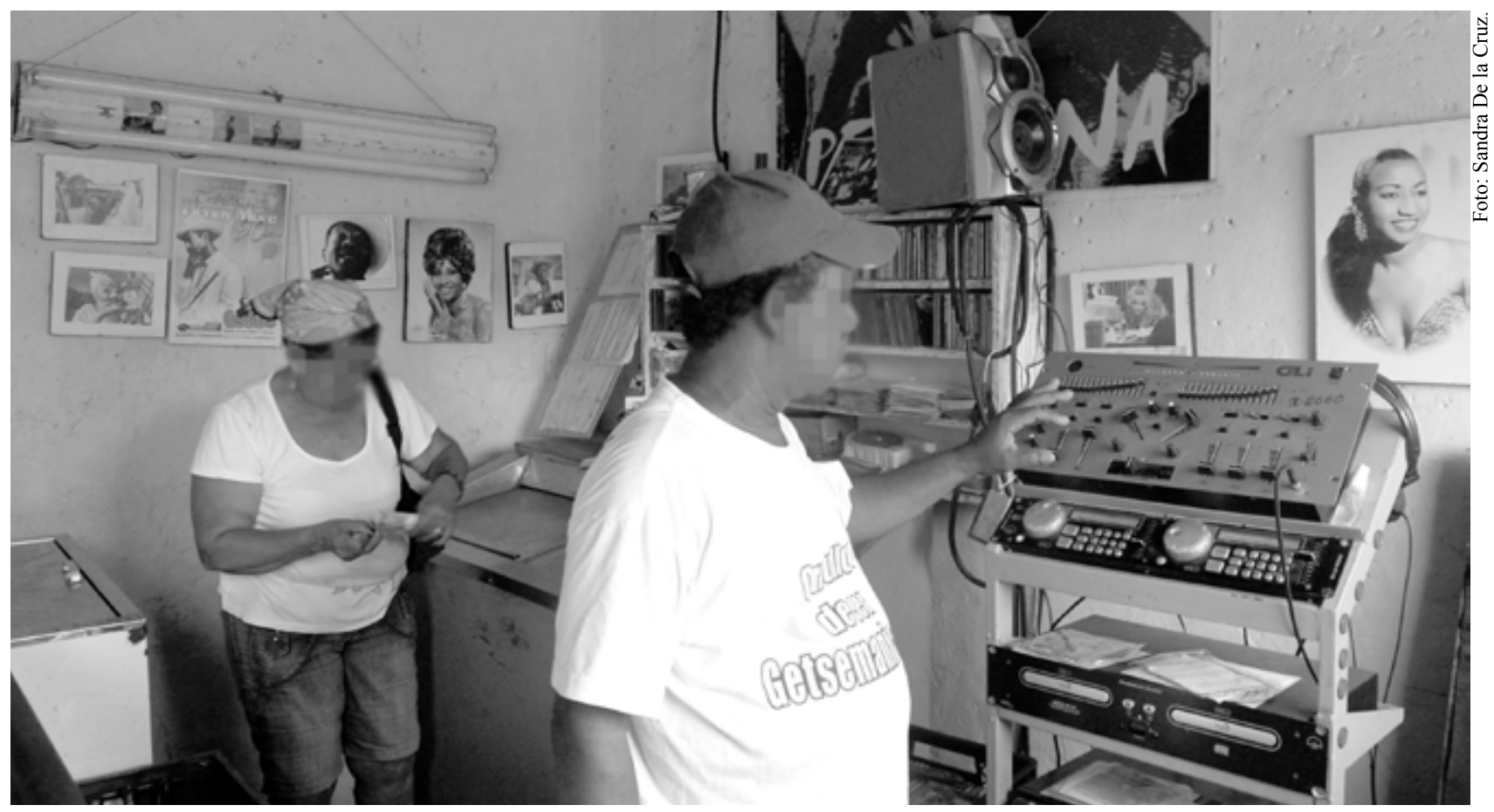

Donde "Tico". Cartagena 2011.

This article attempts to provide a lecture of the gender concept in its interpretation as a social power from the process of masculinity materialization, from performative references that institute an illusion effect of natural and coherent stability in the male body. This is a theoretical work based on the stories of men who have been made and undone by restrictive gender mechanisms that allows a re-reading of the concept of gender in their practice of restraint and subjectivities construction.

Keywords: Gender, restraint, power, body, performativity.

\section{Introducción}

\section{El género no se construye, se materializa. ${ }^{2}$}

Es común en las ciencias sociales hablar de la construcción de los fenómenos sociales, pero a las preguntas icómo se da la construcción? ¿Qué elementos y estrategias de poder permiten que la construcción se lleve a cabo? ¿Existen los sujetos sociales del género antes que los reglamentos que le dan sentido a su constitución en un escenario social? (Betancourth, 2010), las respuestas posibles entran en disputa con lo conocido. Por ello, el artículo busca problematizar los reglamentos de género y la categoría misma, como concepto normativo que solo funciona como un dispositivo denominador de tales reglamentos pues la sujeción se emplea, desde la perspectiva de Foucault, para hablar del proceso por medio del cual el sujeto es "sujetado" por las

2 La mayoría de los argumentos aquí planteados se han publicado en el capítulo III titulado Hacer masculinidades y materializar cuerpos y vida cotidiana. Ver: Dora Inés Munévar M. (Editora). 2010. El verbo hacer en las 2010. El verbo hacer en las investigaciones de género. Bogotá: Editorial Universidad Nacional de Colombia. Págs. 101-158. 
${ }^{3}$ El historiador Thomas W Laqueur en su libro La construcción del sexo. Cuerpo y género desde los griegos hasta Freud, muestra que las categorías de lo femenino y lo masculino como dos entidades separadas es una invención de la modernidad, cuando se establece todo un proceso de significación de la anatomía sexual femenina, estableciendo nuevos lenguajes y mecanismos de poder/saber para materializar las diferencias de género partiendo de la base biológica. mismas leyes que lo identifican, por los mismos mecanismos discursivos que lo limitan, lo circunscriben y sustentan la lectura de las acciones que configuran su propia existencia (Foucault, 1993:37-51).

Hablar así conlleva a pensar que el género es el primer indicador social que expresa la condición de humanidad de cada sujeto para ser leído como tal en una matriz de poder, con la cual se reglamentan las formas de actuación y se regulan los modelos, los fantasmas y los repudios del mismo sujeto para ratificar su identidad de género, el género se hace y se des-hace por los mismos reglamentos que lo sujetan y producen (Butler, 2006:68) así como se intenta mostrar de forma teórica y a partir de las prácticas sociales, como el género se materializa en los cuerpos y no solamente se convierte en un tema, en una acción nominal a la espera de ser construida.

Hay una concepción bastante generalizada en el conocimiento científico y en los saberes que circulan en la cotidianidad para la explicación de los cuerpos marcados por un sexo. La idea revela que existe una realidad biológica del sexo y que el género por más que se resista decir lo contrario, debe establecer la coherencia bio-cultural, entre el sexo biológico, representado de forma plástica por los órganos, las apariencias masculinas y femeninas y las actuaciones que los sujetos establezcan a partir de esa constitución (Laqueur, 1992:102). Esto ha implicado que haya hasta hoy, un solo sistema de saber del género que parte de la constitución de lo masculino y lo femenino como si fuesen categorías que siempre han estado plasmadas en el sistema de pensamiento occidental $^{3}$ y que a su vez, lo que se busca es generar una "naturaleza del sexo" anterior a cualquier forma de significación, que sirve de base para implantar de manera específica, los principios que regulan el género (Butler, 2002:18).

La idea propuesta por el discurso científico y social es simple, pero requiere de mucha explicación para sostenerla. El género se ha montado sobre una estructura que se sustenta sobre la base fundada en la anatomía de los genitales, se parte de la visualización de lo que podría ser un indicador esencial para estructurar desde ese punto las adhesiones de género (Laqueur, 1994:55), "iiEs niño!! ¿Por qué lo sabes?, porque tiene un pene" y desde este instante empieza toda una panoplia de elementos protésicos de género a dar coherencia a la evidencia biológica (la ropa, los colores, las posturas) esta ecuación sexo-biológica-género-cultura, no queda muy clara al momento de preguntarnos ¿Por qué esta realidad bio-social no es estable en el tiempo? ¿Por 
qué se requieren de mecanismos disciplinarios permanentes para poder sedimentar en los cuerpos la coherencia naturalista del sexo y los discursos sociales de género? Toda esta concepción esencialista del cuerpo es lo que Foucault llama un "ideal regulatorio" (Butler, 2002:18), pues el sexo funciona como norma y da un efecto-ilusión de una naturaleza que incluso está antes de cualquier formación discursiva sobre el género (Ibíd.). Cuando se dice que el discurso científico y social sobre la mecánica del género requiere de una explicación que sostenga la idea de la base biológica de los cuerpos, se está impugnando la legitimidad de la estrategia discursiva sobre la naturaleza del sexo, pues este es una ficción normativa que no resiste una revisión desde el mismo género.

El sexo es un discurso histórico, que se ha mantenido en la base social recubierta, resguardada en el discurso de la naturaleza biológica, permite el análisis de los cuerpos partiendo de un principio que se presenta ante todos y todas como estable. Esta idea simplista de mirar las constituciones de los cuerpos ha estado generalizada y sustentada hasta la saciedad por el discurso tecno-científico, obviando de manera deliberada que la naturaleza misma tiene una historia y que no existe en el mundo de lo simbólico y por extensión en lo real, ningún sujeto que preexista a las significaciones de género (Butler, 2006:69).

En efecto, no hay naturaleza del sexo, sino un discurso de género que materializa en los cuerpos una idea histórica de naturalización del sexo que contiene los cuerpos con género (Butler; 2001a:16). Es así, como no existe una naturaleza previa al género que interviene sobre los cuerpos como una superficie pasiva que solo se deja colonizar, penetrar - para utilizar un discurso masculinizado- es el discurso del género que crea una matriz de poder/saber que contiene y explica al sexo. Un cuerpo con un sexo solo es posible que emerja en un entramado simbólico de representaciones de género. Entonces, se puede decir hasta aquí cuando se hace la pregunta ¿qué es el género? se entiende como la matriz reguladora y creadora de todas las formas de legibilidad del cuerpo, el principio fundamental de todas las acciones humanas, que contiene relaciones de saber/poder y se establece a partir de procesos de producción y sujeción de las realidades corporales (Ibíd.). Esta idea subvierte la concepción tradicional y momificada, que el género parte de una esencia biológica, qué es la naturaleza la base para empezar la producción cultural de los cuerpos.

La mecánica discursiva del género como ya se ha señalado (de manera intencional) es contraria a las formas como se han concebido los cuerpos: 1) no existe un sexo sin género, pero si puede existir en el entramado social 
un género sin sexo, esto lleva deliberadamente a sostener 2) que el cuerpo no es una entidad pasiva donde se posa la naturaleza, es, por paradójico que parezca, una materia activa de asunción de posibilidades históricas y culturales de asumir y materializar una multiplicidad de estilos y formas corporales, a partir de una diversidad de actos, "El cuerpo sólo se conoce por su apariencia de género"- dice Judith Butler- es decir, el cuerpo se hace haciéndose y ese hacerse solo es posible dentro del género (Betancourth, op. cit:113); que prescribe unas acciones que ya han estado ensayadas históricamente, ser mujer o ser hombre son actos que obligan al cuerpo a conformarse con una idea histórica de feminidad y masculinidad. Este principio de la mecánica discursiva del género se sostiene en que esos actos de género que representan al género tienen consecuencias punitivas, 3) pues, el género es un poder que crea poderes que dan la sensación de una estabilidad en el cuerpo, pero la forma como el sujeto llega a hacerse, se presenta a través de la puesta en escena de un papel asignado cultural o genéricamente. Papel que si no se interpreta con cuidado llevaría a que el sujeto sea castigado por la sociedad.

Este proceso performativo del género permite la movilidad del cuerpo y ubica al poder en un espacio cotidiano conflictivo, en una ontología del movimiento, en la des-momificación de la relación cuerpo-género, ya que al sustentar la idea, que son las acciones cotidianas las que producen diariamente el proceso de significación y asignación corporal de los géneros, que son interpretados como normales o desviados, como masculinos y femeninos, el poder se materializaría en las acciones que se hacen poder. Este análisis permite contextualizar el género como un poder social que produce el escenario y las acciones, ampliando la perspectiva de análisis que solo perciben el poder como una fuerza que embiste a los sujetos y los domina por los efectos de su fuerza (Zizek, 2005:267).

El poder es el resultado de las acciones, pero también son las acciones las que están condicionadas, sujetadas por las relaciones de poder. Esto quiere decir que el género como poder social, se instituye como una estructura que produce lo que pretende controlar (Butler, 2001b:104-105). La identidad sobre la que se moldea el género es una imitación sin origen, no hay una base donde se empieza a edificar la identidad de género, el sujeto emerge dentro de la matriz reguladora del género y son las normas culturales del género, como la masculinidad y la feminidad, las que hacen posible la aparición de un sujeto, su viabilidad, como cuerpo que puede vivir en esta estructura social, en este terreno ortopédico (Ibíd.). 
La dirección de esta red de palabras, lleva a pensar que no existe sujeto ni antes ni después del proceso de generización ${ }^{4}$ por esa razón ni el género puede ser construido como tampoco se puede pensar en un voluntarismo o un esencialismo cultural o biológico. Los cuerpos son materializados por un proceso de repetición de actos ejecutados de manera permanente en el tiempo, en la cotidianidad; como señala Pierre Bourdieu (2000: 127) son hábitos que se materializan y esa materialización lleva implícito un estándar de imitación de los modelos normativos de género que sancionan las malas copias. Esto quiere decir que las repeticiones cotidianas de las normas de género son las que crean el género, pero que a la vez esas normas de género, esos mecanismos de ortopedia social, son anteriores a cualquier acción humana, como lo plantea Judith Butler: "si la existencia humana es siempre generizada, extraviarse del género establecido es poner en cuestión la propia existencia".(Butler, 2001b:171).

\section{Des-naturalización y el biogénero.}

Abreviando todo lo anteriormente dicho, un sujeto "Estevana", una transgénero quien suele repetir una idea como si fuera una verdad incuestionable sobre su cuerpo-género expresa:

“...cuando era niño, sentía que ese cuerpo no me pertenecía, estaba atrapada en un cuerpo que no era el mío, siempre me gustaron las muñecas, los juegos con las niñas, mi identidad fue homosexual desde el principio. Para eso no hay explicación $\{. .$.$\} nací mujer en$ un cuerpo de hombre..."

La idea enunciada en sus labios es que hay una prisión en su forma material que supera las demás estructuras arquitectónicas de las instituciones penitenciarias, pero el gris, de la reclusión se aclara al compararla con su poder de sujeción, o proceso de devenir subordinado al poder y proceso de devenir en sujeto. Se ha pensado por siglos que "el cuerpo es la prisión del alma", argumento anclado en todo el sistema de pensamiento occidental proponiendo formas de explicación de modelos de género que no reflejan o no dejan emerger una nueva interpretación de las conductas apropiadas para el cuerpo. Estar recluido en un "cuerpo ajeno" es una desdicha para la condición de cada sujeto, pues vivir una vida sin identificarse con los elementos plásticos que impone el género desde el comienzo, crea una "des-orientación", no hay coherencia en el plan divino de vivir en este mundo como un ser humano reconocible, como un ser que deba ser leído según la normativa de género impuesta (Butler, 2006:69).

${ }^{4}$ Generización se entiende aquí como el proceso mediante el cual el sujeto es asignado y asume una descripción de género que le da sentido a su constitución como sujeto vinculado al género.

Entrevista realizada a joven de 24 años de profesión peluquero que vive en la ciudad de Cartagena. Al conceder la entrevista, de la cual se retoma amplia la cual se retoma amplia información, impuso como condición para la utilización de los datos que se le llamara por su nombre actual: "Estevana". Esta entrevista se realizó el 26 de agosto de 2006 respetando los protocolos de protección proidentidad de las personas que colaboran con la investigación. 


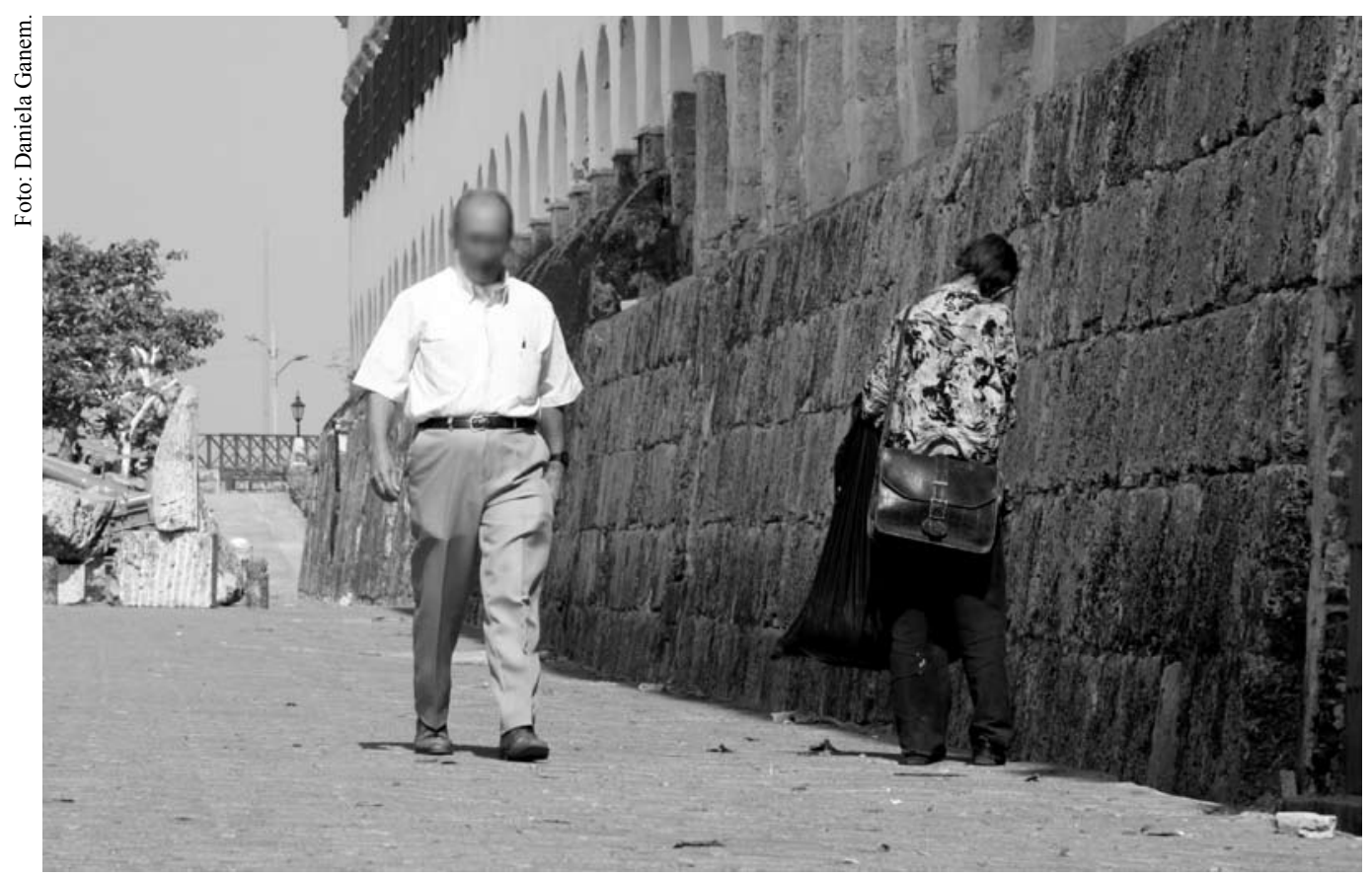

En la ronda. Cartagena 2011.

"Estevana" obliga a pensar de manera múltiple; su grito de angustia choca con los límites de la ortopedia social, con las fronteras de lo permitido sobre su propio cuerpo. Su des-identificación es síntoma de que se ha perdido algo, que el cuerpo vaga por terrenos resquebrajados por su propia elección existencial de género. Como el loco en "La muerte de Dios" de Nietzsche (2004:23), desquiciado en el camino emprendido para la búsqueda de ese Dios, sabiendo de entrada que está muerto y que ha sido él su ultimador, este sujeto, este cuerpo-trans-formado, incurre en ese mismo acto. Sabe que pone en cuestión lo que el "curso natural" de las cosas dichas y vistas ha mostrado por siglos; que el sexo es la base fundamental de la constitución corporal, que tener pene, testículos y otras formaciones plásticas y visuales es un indicador esencial para establecer la identidad de un cuerpo de hombre, pero, su lógica somática, su lectura de la estructura de género sigue anclada en el discurso ambivalente que él o ella misma rechaza $y$, a la vez, le sirve de terreno para "hacerse" a un género. Las puertas de la celda corporal se cierran de manera permanente, la prisión de lo natural o, mejor, de lo naturalizado (Derrida, 2000), funciona como orden disciplinario para organizar las palabras; el panóptico de la explicación de género sigue su marcha, no hay escapatoria, no se avizoran líneas de fuga en el discurso sobre el género.

Parece que la lógica del cuerpo-prisión se fortalece cada vez que se expresan en "cuando era niño, sentía que ese cuerpo no me pertenecía"; con certeza en el juego de las formaciones, en el escenario performativo, emerge esa especie 
de alma de género encerrada en un cuerpo biológico hasta ahora atrapada por redes de significaciones culturales. Lo performativo se entiende como la repetición de significantes de género, que se materializan en el cuerpo a través de sus producciones de poder. Lo natural en este caso queda inscrito en la piel, el cuerpo ha encapsulado en su interior unas transformaciones que parecen venir desde afuera, que le dan sentido cultural a una posible desviación de la norma de género. "El malestar del género" que plantea "Estevana" es la incoherencia natural para dar sentido a una práctica performada como identidad homosexual, "mi identidad fue homosexual desde el principio, agrega "para eso no hay explicación", pero la hay por la constricción impuesta a esa alma que reclama salir para liberarse de ese cuerpo que la tiene atrapada.

El relato de "Estevana" es un argumento más cotidiano de lo que parece. El discurso del cuerpo ajeno es un mecanismo de poder que cerca al género y eleva la explicación social de las acciones a espacios naturalizados, cuyo origen biológico es posible establecer. Como un Dios que levanta su mano para darle forma a lo que no la tiene para crear un mundo en siete días, el discurso del poder de "Estevana" tiene el mismo efecto.

Para empezar, algo que puede condenar, asumiendo que no hay un género homosexual y que tampoco la homosexualidad es un género, lo que se lee es el resultado de un conjunto de acciones del presente performando, la idea de una identidad natural ubicada por siempre en ese sitio, aunque haya estado subyugada por un cuerpo que no la dejó ver la luz del día. Entonces, esa alma de la que se ha hablado en estas líneas, encerrada por la prisión del cuerpo, no es más que una ficción, esa alma es un instrumento de poder, un ideal normalizador que le da un estatus ontológico al cuerpo, esa alma es el género, es un modo de situar al sujeto en un lugar para sujetarlo (Butler, 2002:97), reiterando con Foucault: "el alma es la prisión del cuerpo" (1984:37). Se invierte la regla; aunque se ha pasado de una visión de posesión a poseído, el cuerpo, culpable por siglos de ser el terreno localizable de las más terribles batallas entre el deseo y la moral, entre el decoro y la lujuria, parece atrapado en otras redes. "La carne es débil" dicen los guardianes de las buenas costumbres (Ibíd., 1987:49).

Se ha pensado más recientemente que el cuerpo es un espacio vacío, invadido por una fuerza externa que lo determina y le da sentido a su existencia. Desde la perspectiva de género se ha trabajado sobre la existencia de cuerpos que nacen pre-determinados para representar un papel de masculinidad o de feminidad en el escenario social. "Sentir que el cuerpo no le pertenece", según lo

Palubra No. 11. Septiembre de 2009 - Agosto de 2010 
dicho, enunciar el discurso "estaba atrapado en un cuerpo que no era el suyo", y reiterar "siempre me gustaron las muñecas, los juegos con las niñas", significa y contiene una posición ontológica ocupada por ese cuerpo en el hoy con una supuesta base en las formas como ha devenido en sujeto. La metáfora del cuerpo ajeno es un mecanismo ortopédico que le da forma y ofrece explicaciones a su subjetividad para apreciar cómo el cuerpo materializa una historia contada desde una base generizada. El cuerpo de "Estevana" no tendría un estatus ontológico por fuera de los actos que lo constituyen; si no se expresara en la ficción regulatoria atada al gusto por las muñecas y los juegos con las niñas, no podría performar una identidad homosexual.

Esto sucede porque ningún cuerpo puede estar por fuera de las normas de género que lo explican. Como dice Merleau-Ponty "el cuerpo no solo es una idea histórica, sino también un conjunto de posibilidades continuamente realizables" (1962), entonces es el cuerpo el que se encuentra encerrado por el género cuando no presenta una forma de definición de las acciones expresadas por un sujeto. Si "Estevana" no recurriera a la regulación de su discurso, normalizándolo como homosexual y haciendo una genealogía que dé como resultado la apariencia de un género estable desde el principio, sus actuaciones en el escenario social no tendrían sentido. Quienes consideran a la homosexualidad como un acto de subversión de los modelos de género podrían estar transitando en una aporía del discurso, pues el cuerpo no tiene explicación por fuera de esas normas reguladoras que lo constituyen e instituyen como un género. Este camino permite situar al género como un indicador primario de las formas como se convierte en hombres, como una marca indeleble que da un sentido de identificación a los actos cotidianos, haciéndolos humanamente posibles dentro del contexto de la ortopedia social.

\section{Performatividad de género.}

El género no es de ninguna manera una entidad estable porque depende del cuerpo para "hacerse", para tener efecto (Butler, 2006:13). Siendo el cuerpo un proceso activo de encarnación de diversas contingencias históricas y culturales, no cabe dentro de las posibilidades interpretativas trabajarlo con un principio unitario estable de sexualización, sino que exige una mirada detenida sobre sus efectos en el tiempo, sobre su devenir. A modo de ahondar en la discusión se propone aquí, que el género no se construye inicialmente como se ha planteado extensamente en la literatura de los estudios de género, 
pues el género que uno tiene o que uno asume, no se construye, se materializa en el cuerpo a partir de operaciones performativas, es decir el género son los elementos simbólicos que cada cultura produce para significar las formas de interpretar las prácticas y discursos que se le asignan a un cuerpo sexuado, que de entrada ya está generizado, pues como se ha planteado no existe sujeto ni objeto por fuera de la matriz de significados que produce el mismo género. Entonces, el género producido culturalmente (lenguaje, símbolos, valores, interpretaciones) se materializa en el cuerpo a partir de la repetición ritualizada de esos productos culturales que le dan sentido de naturalidad masculina y/o femenina, que solo se expresan en un escenario de constricción que permite la viabilidad de las formas de repetición que estabilizan el género que uno tiene, o el género que ha sido impuesto. Esta operación de poder de repetición de los códigos en los escenarios constrictivos u ortopédicos como se la denominado se definen como prácticas performativas (Butler, 2002:145).

"Estevana" en este caso, performa una realidad en la medida en que ocurre su propia actuación y con la creencia en su identidad homosexual encerrada por los músculos, vigilada por el panóptico del pene, que entre otras cosas, no dice nada sobre el hecho de ser varón; este orden simbólico de las cosas es el efecto de estabilidad que quiere dar el orden de género para garantizar el imperio heterosexual que le da sentido social a los actos mediante los cuales se está materializando su cuerpo. Hasta ahora, sobre todo con la mirada puesta en el cuerpo de "Estevana" y escuchando sus propias palabras, se ha expuesto la forma como la ortopedia social se hace carne, con un proceso vivido en los cuerpos como una figuración necesaria para la existencia. Por lo pronto se dice: la performatividad de género no es solo actuación, es una condición para asegurar la subsistencia de un cuerpo en el orden simbólico del género (Betancourth, op.cit).

Otro ejemplo de la performatividad, de la repetición ritualizada de convenciones de estilos para realizar (Austin, 1988) o hacerse a un género en un cuerpo masculino, se encuentra en las líneas de una planilla de ingreso de un hospital psiquiátrico local. Esta historia es muy particular; en pocas líneas revela los mecanismos ortopédicos para performar en el sujeto una idea de masculinidad perdida, en una época de la vida "por realizar", acciones no permitidas en el manual de reglamentos de la masculinidad. Se llamará a este personaje, señor " $\mathrm{K}$ ".

"Paciente, K, de 28 años de edad, que ingresa el día 31 de mayo de 2007, es traído por su tío ya que tiene antecedentes de consumo de

Palubra No. 11. Septiembre de 2009 - Agosto de 2010 
sustancias psicoactivas de 10 años de evolución, refiere consumo de cocaína, marihuana y bóxer... Su historial muestra un trastorno en el comportamiento por una distorsión perceptiva de su género. La madre ha dormido en la misma cama con el paciente a lo largo de su vida. Vive con las hermanas y no tuvo en la infancia y en la adolescencia, referentes masculinos. Ha estado en el ejército, se volvió policía profesional, se niega a aceptar su homosexualidad, emplea sustancias para ser más agresivo, dice el paciente que es mejor volverse loco que marica. Al ingreso el paciente se encuentra hostil, poco colaborador y con heteroagresividad.".

El caso revela más silencios que verdades a voces, pero de manera clara da a conocer los mecanismos de ortopedia social con los cuales se estructura una figuración ideal de masculinidad a partir de una acción situacional. Se dice en la historia clínica que "el origen" de la enfermedad mental data de una práctica que no debe presentarse en la construcción de la identidad de género y es el no tener "referentes masculinos". No tener un modelo de imitación de género no contribuye a la realización de la coherencia entre el sexo y el género que se intenta sostener. Lo particular de este caso es que el mismo sujeto ha empleado una serie de mecanismos ortopédicos como coadyuvantes para la corrección "de las deformidades corporales". La mecánica de la corrección a la que se somete el sujeto para alcanzar una masculinidad normalizada se puede interpretar en el hecho que haya ingresado a instituciones socialmente reconocidas como disciplinarias. Someter el cuerpo a la disciplina militar es un indicador que muestra el desespero del sujeto por entrar en "las rutas de la masculinidad", como señala Rafael Montesinos (2002).

No hay nada que extraer o suprimir de este caso, no se puede interpretar como omisión; el sujeto está representando unas actuaciones de género que lo performan como masculino: agresividad, consumo de sustancias, demostraciones de valentía, para "hacer" un cuerpo diferente al preformado en su núcleo familiar. Opta por estos mecanismos para poder representar el fantasma normativo de la "masculinidad ideal" que tanto acecha los cuerpos de los hombres. Lo extremo de esta interpretación se expresa en los instrumentos adoptados para reforzar su actuación de género, el consumo de sustancias para actuar con agresividad, un rasgo políticamente sustentado en el orden de género para estructurar los reglamentos y los actos que se

${ }^{6}$ Archivo de epicrisis y planillas de ingreso. Clínica Turbaco-Bolívar 2007. 
los indicadores de género que más se ajustan al modelo de normalización de un cuerpo masculino (Buring y Meler, 2002:199). El paciente asume el papel de agresivo como una forma de buscar una masculinidad que supuestamente está afuera de él y que la historia personal lo ha condenado a vagar en la incertidumbre hasta encontrarla.

En el libro "Varones", Mabel Burin e Irene Meler dedican un capítulo para el análisis de la hostilidad como indicador de la masculinidad, ellas afirman que: "la hostilidad es una de la conductas más controversiales cuando procuramos entrelazar hipótesis psicoanalíticas con teorías sobre la construcción social de la subjetividad masculina: unas ponen el acento en los movimientos pulsionales $y$ sus destinos, otras enfatizan las formaciones culturales que inciden sobre la construcción genérica de los varones y su procesamiento de la hostilidad"(ibid).

La historia de este vagabundo que transita por espacios del género y la enfermedad mental, muestra la forma como la enfermedad mental está sujetada a unas representaciones que construye el mismo género para poder determinar los cuerpos con categorías normalizadoras. Dormir con la madre, tener solo hermanas, buscar referentes de masculinidad en instituciones como el ejército, luego volverse policía como un acto de representación de virilidad, es una interpretación basada en el género que condiciona los diagnósticos y establece de forma permanente los mecanismos ortopédicos para la "corrección de su alma". Pero cuando el relato enfatiza que el sujeto prefiere "volverse loco antes que marica", se observa la fuerza con la que emerge la performatividad, la sedimentación del "realizarse" como acto de imitación y castigo con las normativas de regulación para permitir la significación de este acto. ${ }^{7}$ Por ahora, se diría a los lectores y lectoras que la interpretación de un caso psiquiátrico se fundamenta en el orden de género para condicionar las interpretaciones que se salen de los modelos hetero-centrados, pues volverse algo permite experimentar el poder productor de los actos en el escenario cotidiano.

La enunciación "volverse loco antes que marica" igualmente destaca que no toda la teoría de la performatividad va dirigida hacia la homosexualidad, y no todo acto homosexual es performativo, como lo han interpretado algunos autores críticos de esta postura teórica. La frase estudiada finalmente muestra que el objetivo de la materialización performativa de los actos no es mostrar la forma como los sujetos ponen el género en disputa, sino que intenta reafirmar los mecanismos heterosexuales, los procedimientos de regulación de la masculinidad ideal, ilustrar en el campo social el modo como los cuerpos
${ }^{7}$ Se podría decir que la locura dentro de su proceso de interpretación y formación "se hace" a través de las interpretaciones performativas de sus síntomas, por cuanto "los locos" performan una patología psiquiátrica, ya que las sacudidas, los gestos las desviaciones de la conducta, son efectos performados. Este tema no cabe en estas líneas, requiere otra investigación sobre la performatividad de la locura, pero contiene la forma como se hacen las deforma como se hacen las de nominaciones de los sujetos dentro de un campo social a partir de actos interpretados en un contexto social e institucional específico. 
son hechos y des-hechos, en espacios conflictivos de poder. "Hacerse" loco antes que "hacerse"-volverse dice el texto original- marica, es una interpretación que despoja las ideas fijas, naturales, inherentes al sujeto, que desplazan los argumentos de las "realidades pulsionales", de la base bio-política de los cuerpos, al escenario político del poder, que forma los géneros que intenta controlar(Butler; 2001b:106). Citar actos que se interpretan como locura, imitar gestos, posiciones, forzar al cuerpo a producir significados que se hacen saberes por la fuerza de la repetición de unos reglamentos, dibujan un haz de luz sobre el terreno problemático de la construcción cultural de los cuerpos que siempre está ocultando sus mecanismos ortopédicos.

La performatividad refuerza el escenario ortopédico de la heterosexualidad, las convenciones que requieren la imitación del sujeto son papeles producidos por la matriz de género siempre plegada a las características heterosexuadas. El caso de "Estevana" que performa una identidad homosexual, ancla su discurso sobre la construcción de su cuerpo en terrenos hetero-centrados que representan la supuesta feminidad de su cuerpo, apela al principio de inversión para que su argumento "sea normal", "sea natural", y no solamente ante los ojos de los hombres. De igual forma, el señor "K", expuesto a un escenario ortopédico, recurre a la normalización de su cuerpo para que el género tenga sentido y las maniobras de corrección puedan actuar de forma acertada, puedan encontrar la masculinidad errante que vaga por espacios reguladores bastante inestables. Es entonces, como lo plantea Agamben (2006:12), "el ser cual-sea", el que es definido por una lógica de poder, arrastrado por unos códigos ya pre-establecidos, responde siempre a su deseo, está en una relación de aferrarse a un discurso que permita su lectura; así el sujeto al ser "cualsea", homosexual, heterosexual, bisexual, trans-género, va a estar definido, denominado, por un orden de género. Sólo a través de su relación con una idea (ibíd.:57) de masculinidad o feminidad, el sujeto, junto con sus acciones y significados, hace posible su viabilidad en este mundo. Las palabras son mucho más complejas de lo que la superficie de los acontecimientos muestra, pero no es un acto solo de voluntad de un sujeto querer volverse, ya sea, loco, homosexual o heterosexual, es en las restricciones que impone el sistema ortopédico del género en el que los cuerpos pueden llegar a ser algo, pueden llegar a ser reconocidos (Butler, 2006:193).

${ }^{8}$ La teoría de la performatividad de género no solamente se despliega en las prácticas de excepción sino que es una postura teórica que devela la reafirmación de las normativas de género en los procesos de normalización de los cuerpos.

\section{Conclusiones. Otros caminos del género}

Lo dicho y lo escrito muestra que el género, aunque conceptualmente debatido, ha sido tan anunciado como verdad que es tiempo de volver a someter sus 
contenidos a nuevos cuestionamientos. Pero después de todo iqué saber ha legitimado una manera de comprender o pensar el género?, ¿qué conocimiento es tan maduro, tan prolijo, para echar un vistazo desde una sola orilla a la constitución del género en su aspecto condicionante de las configuraciones fijas de masculinidad y feminidad? Es fácil para la voz de todos y todas hablar de la forma ya instituida, repetir de manera permanente el discurso que agrada. La retórica del género se ha performado de tal manera que ha perdido su sentido, su capacidad de agenciamiento, ha quedado encerrada en la fortaleza del poder.

Bien lo decía la profesora Dora Munévar, "se dice tanto del género, se utiliza tanto la expresión, que se ha vaciado de contenido" (2010). No obstante, la hipótesis básica de este trabajo no consistía en mostrar el desgaste del género, su debilitamiento o la forma como lo está utilizando el poder, como si existiera una estructura amplia que redujera al género a un simple indicador de la condición humana. Lo que está en crisis, lo que se está "vaciando de contenido" es la manera de interpretarlo, son las formaciones discursivas que han capturado el concepto volviéndolo una herramienta usable, un procedimiento a seguir, una categoría aislada, un concepto fijo, una estrategia aditiva que finalmente no expresa el potencial argumentativo de toda la analítica del género.

Lo importante de este trabajo ha sido debatir el paradigma del poder subyacente en las relaciones de género, no como un poder externo que sirve de referencia para mirar las relaciones de dominación o para medir las fuerzas que movilizan

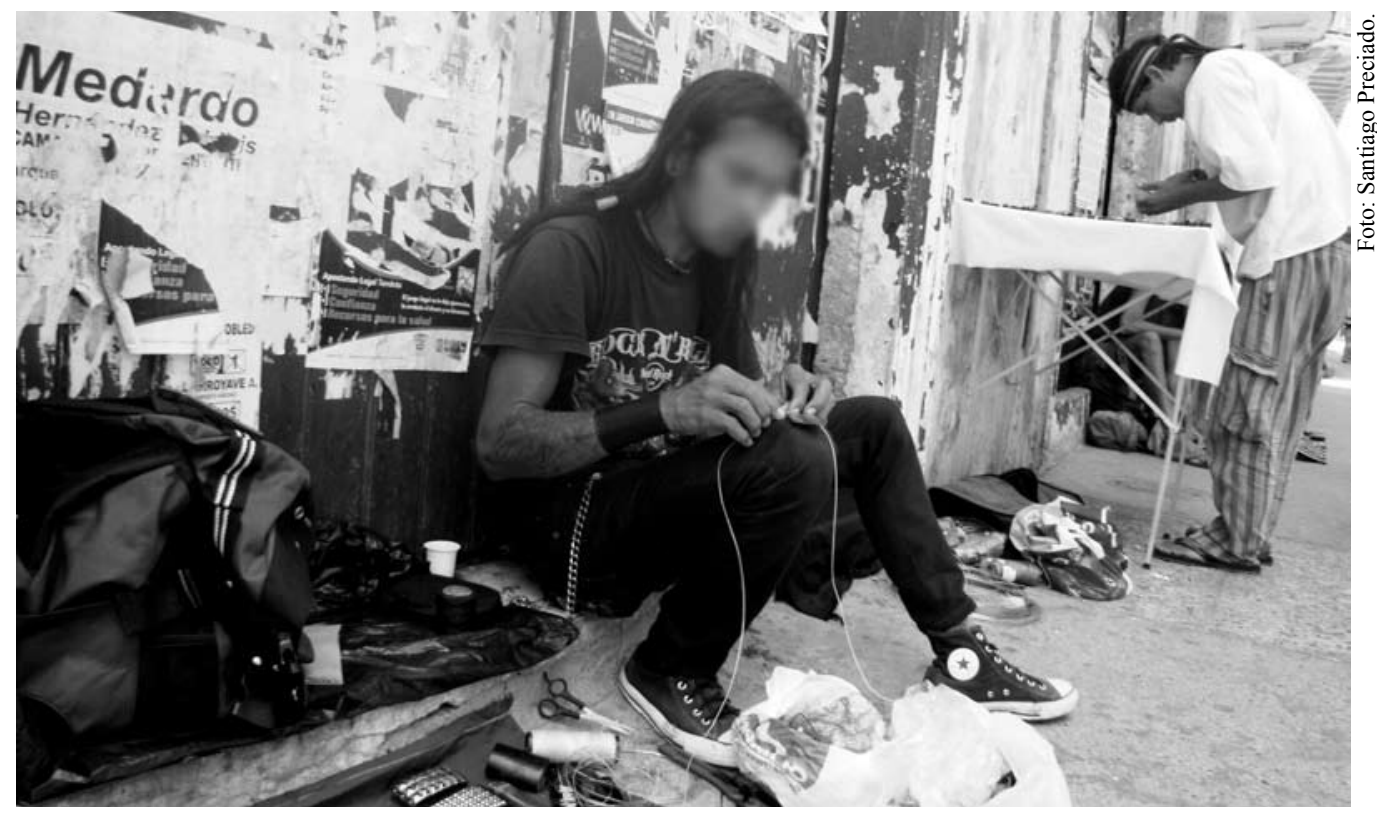

Tejedor. Cartagena 2010.

Palobra No. 11. Septiembre de 2009 - Agosto de 2010 
otras fuerzas en una dinámica de poderes y resistencias. Existe un "orden de género" que ha pasado inadvertido porque sus mecanismos provienen de fuera, una especie de máquina de captura en términos de Gilles Deleuze, usada para prescribir prácticas de comportamiento, imponer límites de pensamiento y constituir las bases legítimas subyacentes en la sanción de las conductas (Deleuze y Guattari, 2006) exigidas por las instituciones sociales. La forma como se han conjurado las relaciones de género se sustentan en el paradigma del poder disciplinario. Los trabajos sobre género que subrayan la importancia de las relaciones de poder en su línea foucaultiana, muestran una realidad de represión, castigo y sometimiento, exponiendo el análisis del poder a una revisión parcial de la complejidad propia de la formación de los sujetos como sujetos a un género. Por eso mismo, pensar el género va mucho más allá de la simple descripción de los roles sexuales, los comportamientos sociales, los mecanismos disciplinarios y los discursos prescriptivos de las formas de vivir, sentir y representar los cuerpos.

Sujeto con un género, pero sujetado por el género (Butler, 2001b:105), no existe una formación de un cuerpo por fuera de las estructuras que expone el mismo género; por tanto, no se puede pensar las acciones corporales sin la fuerza de un escenario de control operando a partir de una lógica diferente a la expuesta por las formas disciplinarias del poder. En términos, específicos el género es una matriz de poder que instituye sus propios mecanismos de disciplina, sus formaciones de saber y sus dispositivos de control; su objetivo es ocultar una génesis basada en el ideal regulatorio del sexo primario y la inestabilidad provocada al colocarlo en disputa, al someterlo a la fuerza de la repetición cotidiana de ciertas prácticas consideradas como naturales o estables: las nociones de masculinidad y feminidad. Queda pues escrito que reducir el género a las nociones de femenino y masculino es una vieja práctica instituida desde el siglo XIX ahora interrogada profundamente. El género es un poder y como forma de poder hay que analizarlo en la multiplicidad de acciones y en la diversidad de interpretaciones para hacer circular los elementos que definen en cada cuerpo la noción de humano que cada quien lleva consigo.

\section{BIBLIOGRAFIA}

AGAMBEN, Giorgio. (2006). La comunidad que viene. Valencia: Editorial Pre-Textos.

AUSTIN, John L. (1988). Como hacer cosas con las palabras. Barcelona: Editorial Paidós.

BETANCOURTH, Germán. (2010). "Hacer masculinidades y materializar cuerpos en la 
vida cotidiana". En: MUNÉVAR, Dora. (Editora) El verbo hacer en las investigaciones de género. Bogotá: Editorial Universidad Nacional de Colombia.

BOUDIEU Pierre. (2000). La dominación masculina. Barcelona: Editorial Anagrama.

BURIN Mabel e MELER Irene. (2002).Varones. Género y subjetividad masculina. Buenos Aires: Editorial Paidós.

BUTLER, Judith. (2001a). El género en disputa. El feminismo y la subversión de la identidad. México: Editorial Paidós.

BUTLER, Judith. (2001b) Mecanismos psíquicos del poder. Teorías sobre la sujeción. Madrid: Ediciones Cátedra.

BUTLER, Judith. (2002). Cuerpos que importan. Sobre los límites materiales y discursivos del "sexo". Buenos Aires: Editorial Paidós.

BUTLER, Judith. (2006) Deshacer el género. Buenos Aires: Editorial Paidós.

DELEUZE, Gilles y GUATTARI Félix. (2006) Mil mesetas. Capitalismo y esquizofrenia. Valencia: Editorial Pre-Textos.

DERRIDA Jacques. (2000). Dar (el) tiempo. Barcelona: Editorial Paidós.

FOUCAULT Michel. (1984). Vigilar y castigar. Novena edición. México: Editorial Siglo XXI.

FOUCAUIT Michel. (1993) Historia de la sexualidad. Vol. I La voluntad de saber. 21 Edición. México: Editorial Siglo XXI.

LAQUEUR, Thomas W. (1992). "Amor veneris, vel dulcedo appeleur". En: Feher, Michel. (Editor). Fragmentos para una historia del cuerpo humano. Madrid: Taurus Ediciones.

LAQUEUR, Thomas W. (1994) La construcción del sexo. Cuerpo y género desde los griegos hasta Freud. Madrid: Editorial Cátedra Feminismos.

MERLEAU-PONTY, Maurice. (1962) "The body in its sexual being". En: Phenomenology of perception. Boston: Routledge and Keagan Paul.

MONTESINOS, Rafael. (2002). Las rutas de la masculinidad. Barcelona: Editorial Gedisa.

MUNEVAR, Dora. (2010). El verbo hacer en las investigaciones de género. Bogotá: Editorial Universidad Nacional de Colombia.

NIETZSCHE, Friedrich. (2004) La muerte de Dios. México: Publicaciones Universidad Autónoma de México.

ZIZEK,Slavoj. (2001). El espinoso Sujeto. El centro ausente de la ontología política. Buenos Aires: Editorial Paidós.

PalObra No. 11. Septiembre de 2009 - Agosto de 2010 